\title{
Synthesis of Zinc Oxide (ZnO), Silver (Ag), Copper Oxide (CuO) and Titanium Oxide $\left(\mathrm{TiO}_{2}\right)$ Nanoparticles
}

\author{
K. Anandaraj ${ }^{*}$, R. Ilakkiya and N. Natarajan \\ Department of Seed Science \& Technology, Tamil Nadu Agricultural University, \\ Coimbatore - 641 003, Tamil Nadu, India \\ *Corresponding author
}

\section{A B S T R A C T}

Keywords

Nano particle, $\mathrm{ZnO}, \mathrm{Ag}, \mathrm{CuO}$ and $\mathrm{TiO} 2$ Nanoparticles, SEM, TEM, Particle size analyzer, Raman spectroscopy

Article Info

Accepted:

12 October 2018

Available Online:

10 November 2018
Zinc oxide $(\mathrm{ZnO})$, Silver $(\mathrm{Ag})$, Copper oxide $(\mathrm{CuO})$ and Titanium oxide $\left(\mathrm{TiO}_{2}\right)$ nanoparticles were synthesised using simple chemical route which were characterised using Scanning Electron Microscope (SEM), Transmission Electron Microscope (TEM), Particle Size Analyzer and Raman Spectroscopy. Size of Zinc oxide ( $\mathrm{ZnO})$, Silver (Ag) Copper oxide $(\mathrm{CuO})$ and Titanium dioxide $\left(\mathrm{TiO}_{2}\right)$ nanoparticles measured $16-50 \mathrm{~nm}, 50$ $100 \mathrm{~nm}, 60-150 \mathrm{~nm}$ and 100-120, respectively to conform the nano-size.

\section{Introduction}

Research in the field of synthesis methodology of nanomaterials is mainly oriented in controlling their shape, size and composition. Each of these factors is a key factor in determining the properties of materials that lead to different technological applications

Zinc oxide, with its unique physical and chemical properties, such as high chemical stability, high electrochemical coupling coefficient, broad range of radiation absorption and high photostability, is a multifunctional material. $\mathrm{ZnO}$ nanoparticles were synthesized by different methods. The process of precipitating zinc oxide was carried out using zinc acetate $\left(\mathrm{Zn}\left(\mathrm{CH}_{3} \mathrm{COO}\right)_{2} \cdot \mathrm{H}_{2} \mathrm{O}\right)$ and ammonium carbonate $\left(\mathrm{NH}_{4}\right)_{2} \mathrm{CO}_{3}$. A simple precipitation process for the synthesis of zinc oxide was carried out by Lanje et al., (2013). Their work was carried out to investigate the synthesis and characterization of $\mathrm{ZnO}$ nanoparticles using numerical simulations and experimental methods.

Silver NPs are of interest because of the unique properties which can be incorporated into antimicrobial applications, biosensor materials, composite fibers, cryogenic superconducting materials, cosmetic products, electronic components and pharmaceutics, medicine. 
Copper oxide nanoparticles (CuO-NPs) were synthesized via chemical precipitation method using copper (II) chloride dihydrate and sodium hydroxide.

$\mathrm{TiO} 2$ is the most investigated photocatalyst system and has been found to be capable of decomposing a wide variety of organics and inorganics in both liquid phase and gas phase.

This paper presents the synthesis of $\mathrm{ZnO}, \mathrm{Ag}$, $\mathrm{CuO}, \mathrm{TiO}_{2}$ nanoparticles by simple method.

\section{Materials and Methods}

The first experiment synthesis of nanoparticles and characterization was carried out at Department of Nano Science and Technology and the second experiment study of seed quality enhancement was carried at Department of Seed Science and Technology, Tamil Nadu Agricultural University, Coimbatore -03 , during the year of 2012-13. The chemicals used for synthesis of nanoparticles viz., Zinc nitrate ( $\mathrm{Zn}$ $\left.\left(\mathrm{NO}_{3}\right)_{2} \cdot 4 \mathrm{H}_{2} \mathrm{O}\right), \mathrm{AgNO}_{3}$, Trisodium citrate, copper nitrate trihydrate, $\mathrm{TiO}_{2}$ pellets, $\mathrm{NaOH}$ and Ethanol were purchased from THE I.L.E. Co. Pvt. Ltd., Coimbatore, Tamil Nadu.

\section{Synthesis of $\mathrm{ZnO}, \mathrm{Ag}, \mathrm{CuO}$ and $\mathrm{TiO}_{2}$ Nanoparticles}

\section{Zinc oxide nanoparticles}

ZnO NPs were synthesized by adding $0.45 \mathrm{M}$ aqueous solution of zinc nitrate $\left(\mathrm{Zn}\left(\mathrm{NO}_{3}\right)_{2} \cdot 4 \mathrm{H}_{2} \mathrm{O}\right)$ and $0.9 \mathrm{M}$ aqueous solution of sodium hydroxide $(\mathrm{NaOH})$ in distilled water taken in two separate $250 \mathrm{ml}$ glass beakers. The $\mathrm{Zn}\left(\mathrm{NO}_{3}\right)_{2}$ solution $(100 \mathrm{ml})$ transferred to a burette was added drop wise (slowly for $40 \mathrm{~min}$.) to the $100 \mathrm{ml}$ of $\mathrm{NaOH}$ contained in the beaker placed over a magnetic stirrer with hot plate set at $55^{\circ} \mathrm{C}$ with high-speed stirring. The beaker after adding
$100 \mathrm{ml} \mathrm{Zn}\left(\mathrm{NO}_{3}\right)_{2}$ was removed from the hot plate, sealed with aluminium foil and kept undisturbed for $2 \mathrm{~h}$ for precipitation and settlement. The precipitated ZnO NPs were washed with millipore water followed by ethanol and then vacuum dried at $60^{\circ} \mathrm{C}$ (Moghaddam et al., 2009). Nanoparticles such synthesized were transferred to air tight screw cap vial $(10 \mathrm{ml})$ and stored at ambient temperature for further investigations.

\section{Silver Nanoparticles}

The Ag NPs were prepared by using chemical reduction method according to the description outlined by (Lee and Meisel, 2005). Fifty milliliter of $\mathrm{AgNO}_{3} 0.005 \mathrm{M}$ taken in a beaker was boiled on a magnetic stirrer with hot plate. To this solution, $5 \mathrm{ml}$ of $1 \%$ trisodium citrate was added drop by drop from $10 \mathrm{ml}$ measuring cylinder with vigorous mixing on the stirrer until pale yellow colour appeared. Then the beaker was removed and kept at ambient temperature where the chemical reaction occurred would have been

$$
\begin{aligned}
& 4 \mathrm{Ag}^{+}+\mathrm{C}_{6} \mathrm{H}_{5} \mathrm{O}_{7} \mathrm{Na}_{3}+2 \mathrm{H}_{2} \mathrm{O} \\
& \mathrm{C}_{6} \mathrm{H}_{5} \mathrm{O}_{7} \mathrm{H}_{3}+3 \mathrm{Na}^{+}+\mathrm{H}^{+}+\mathrm{O}_{2} \uparrow
\end{aligned}
$$

\section{Copper oxide nanoparticles}

$\mathrm{CuO}$ NPs were synthesised using copper nitrate trihydrate $\left(\mathrm{CuN}_{2} \mathrm{O}_{6} \cdot 3 \mathrm{H}_{2} \mathrm{O}\right.$, SigmaAldrich), and sodium hydroxide anhydrous pellets $(\mathrm{NaOH}$, Carlo erba) in the presence of polyvinyl alcohol (PVA, Sigma Aldrich) as starting precursor (Wongpisutpaisan et al., 2011). Sodium hydroxide was dissolved in deionized water and thus obtained solution $(0.5 \mathrm{M}, 50 \mathrm{ml})$ was added drop wise to an aqueous $\mathrm{CuN}_{2} \mathrm{O}_{6} .3 \mathrm{H}_{2} \mathrm{O}$ solution $(0.1 \mathrm{M}, 50$ $\mathrm{ml}$ ) for $30 \mathrm{~min}$. Sonication of the solution was performed using Sonics Model VCX 1500 until complete precipitation. Finally, precipitated powder was calcined at $600^{\circ} \mathrm{C}$ for $2 \mathrm{~h}$ to obtain the nanoparticles. 


\section{Titatium oxide nanoparticles}

$\mathrm{TiO}_{2}$ NPs were synthesized by dissolving $0.5 \mathrm{~g}$ $\mathrm{TiO}_{2}$ pellets in $30 \mathrm{ml}$ of $\mathrm{NaOH}$ solution $(10 \mathrm{M})$ under vigorous stirring at room temperature for $2 \mathrm{~h}$. Thus obtained yellow solution was irradiated in an ultra sonicator (Soncis, VCX $1500,20 \mathrm{kHz}$ and $350 \mathrm{~W}$ ) for $2 \mathrm{~h}$ in ambient temperature. The resultant precipitate was then centrifuged, washed and decanted with deionized water several times and dried at $60^{\circ}$ $\mathrm{C}$ for $24 \mathrm{~h}$ to obtain the nanoparticles (Arami et al., 2007).

\section{Characterization of synthesized nanoparticles}

Characterization of the synthesized nanoparticles was performed by using Scanning Electron Microscope (SEM), Transmission Electron Microscope (TEM), Particle Size Analyzer and Raman Spectroscopy.

\section{Scanning Electron Microscope (SEM)}

FEI QUANTA 250 was used to characterize the size and morphology of the nanoparticles. Sample of test nanoparticles ( 0.5 to $1.0 \mathrm{mg}$ ) was dusted on one side of the double sided adhesive carbon conducting tape, and then mounted on the $8 \mathrm{~mm}$ diameter aluminum stub. Sample surface were observed at different magnification and the images were recorded.

\section{Transmission Electron Microscope (TEM)}

FEI TECHNAI SPRIT make was used to analyze the sample. Dilute suspensions of NPs $(0.50 \mathrm{mg})$ in pure ethanol $(15 \mathrm{ml})$ were prepared by ultrasonication.

A drop of the suspension placed on 300-mesh lacy carbon coated copper grid upon drying, was examined and the images were recorded at different magnification.

\section{Particle size analyzer}

The particle size analyzer was used to determine the particle size and the distribution pattern of synthesized $\mathrm{ZnO}, \mathrm{Ag}, \mathrm{CuO}$ and $\mathrm{TiO}_{2}$ nanoparticles. The particle size distribution (PSD) of a powder indicates a list of values or a mathematical function that defines the relative amount of particles present, sorted according to size.

In the present study, HORIBA nanoparticle size analyser SZ 100 was used. Accurately, $0.5 \mathrm{mg}$ of sample was dispersed in $10 \mathrm{ml}$ pure water through ultrasonication and the measurements were taken.

\section{Raman spectroscopy}

Raman spectroscopy is a spectroscopic technique based on inelastic scattering of monochromatic light, usually from a laser source. Inelastic scattering means that the frequency of photons in monochromatic light changes upon interaction with the sample. Photons of the laser light are absorbed by the sample and then reemitted. Frequency of the reemitted photons can be shifted either up or down in comparison to the original monochromatic frequency which is called the Raman Effect. This shift provides information about vibrational, rotational and other low frequency transitions happening in the molecules. Raman spectroscopy can be used to study solid, liquid and gaseous samples.

Raman spectrum is a spectral "fingerprint". If number of different compounds is present in a mixture, the resulting Raman spectra will be a superposition of the spectrum of each of the components. The relative intensities of the peaks can be used to give quantitative information on the composition of mixture of known compounds. The Raman spectrum was measured for the synthesized nanoparticles using Raman spectrum Model- R- 3000- QE. 


\section{Characterization of nanoparticles $\left(\mathrm{ZnO}, \mathrm{Ag}, \mathrm{CuO}\right.$ and $\left.\mathrm{TiO}_{2}\right)$}

\begin{tabular}{|c|c|c|}
\hline \multirow[t]{2}{*}{ Nanoparticles } & \multicolumn{2}{|c|}{ Morphological Descriptions } \\
\hline & SEM & TEM \\
\hline $\mathrm{ZnO}$ & $\begin{array}{l}\text { Lanceolated nanoscaled rods } \\
\text { measuring } 50-80 \mathrm{~nm} \text { diameter; } \\
\text { appeared to be radiating from a central } \\
\text { core (Plate 1a) }\end{array}$ & $\begin{array}{l}\text { Rod shaped fused at centre to form a } \\
\text { radiating structure as observed in SEM } \\
\text { (Plate } 2 \mathrm{a} \text { ) }\end{array}$ \\
\hline Ag & $\begin{array}{l}\text { Appeared as a bundle of spheres } \\
\text { measuring for } 400-450 \mathrm{~nm} \text { (Plate } 1 \mathrm{~b})\end{array}$ & $\begin{array}{l}\text { Spherical in shape with a size ranging } \\
\text { from } 50-100 \mathrm{~nm} \text { (Plate } 2 \mathrm{~b} \text { ) }\end{array}$ \\
\hline $\mathrm{CuO}$ & $\begin{array}{l}\text { Uniform spherical to oval sized } \\
\text { particle measuring } 60-150 \mathrm{~nm} \text { (Plate } \\
\text { 1c) }\end{array}$ & $\begin{array}{l}\text { Uniform crystalline particles } \\
\text { measuring } 80-140 \mathrm{~nm} \text { (Plate } 2 \mathrm{c})\end{array}$ \\
\hline $\mathrm{TiO}_{2}$ & $\begin{array}{l}\text { Irregular spherical shaped peanut like } \\
\text { particle with an average diameter of } \\
120 \mathrm{~nm} \text { (Plate 1d) }\end{array}$ & $\begin{array}{l}\text { Rutile nano particle, primarily } \\
\text { tetragonal in shape with an average } \\
\text { size of } 100 \mathrm{~nm} \text { (Plate } 2 \mathrm{~d}) \text {. }\end{array}$ \\
\hline
\end{tabular}

Plate.1 SEM images of (a) Zno, (b) silver, (c) $\mathrm{CuO}$ and (d) $\mathrm{TiO}_{2}$ nanoparticles

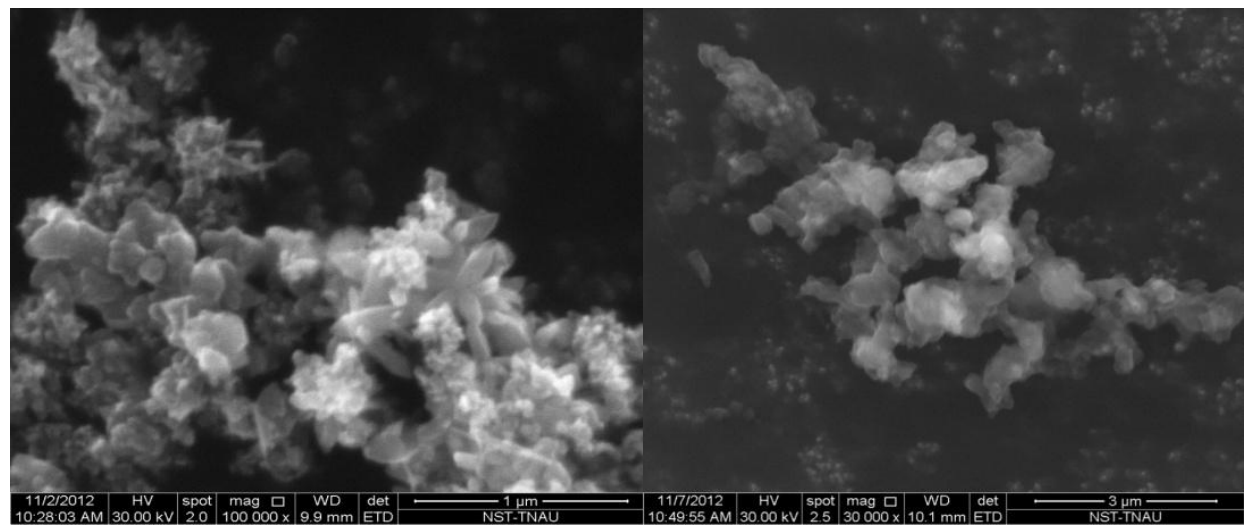

(a)

(b)

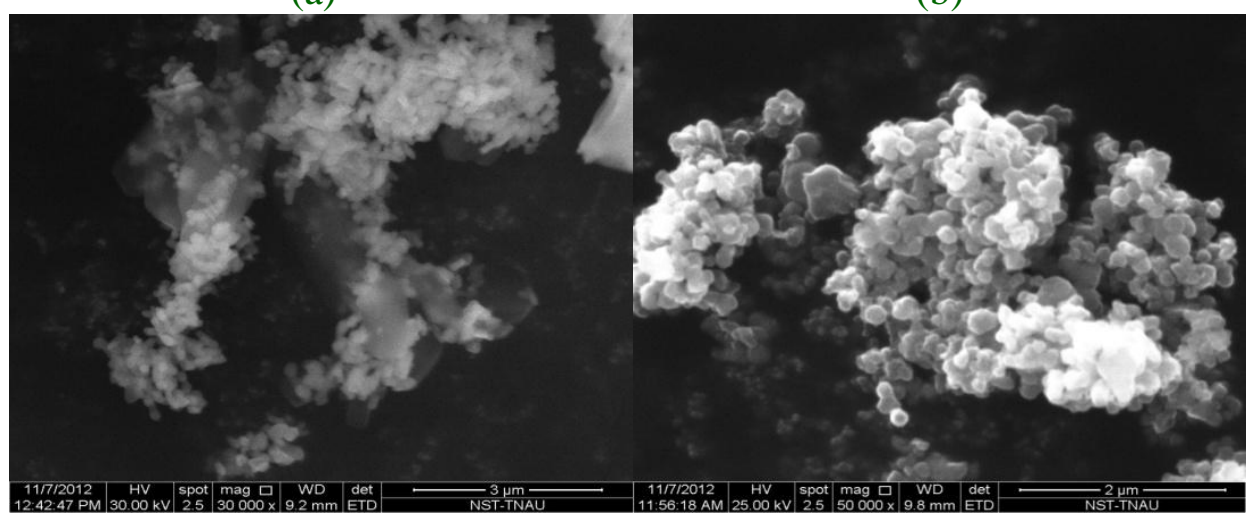

(c)

(d) 
Plate.2 TEM images of (a) $\mathrm{ZnO}$, (b) silver, (c) $\mathrm{CuO}$ and (d) $\mathrm{TiO}_{2}$ nanoparticles

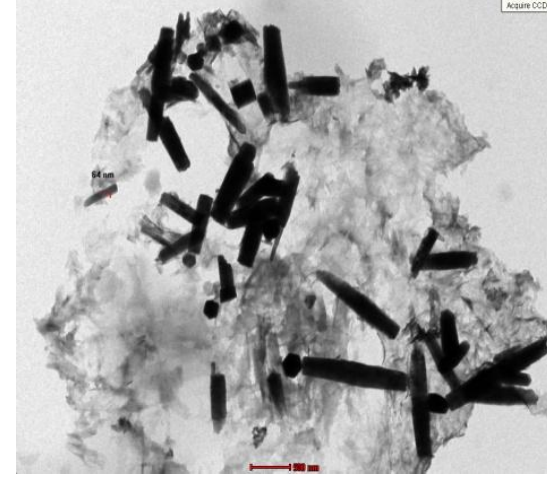

(a)

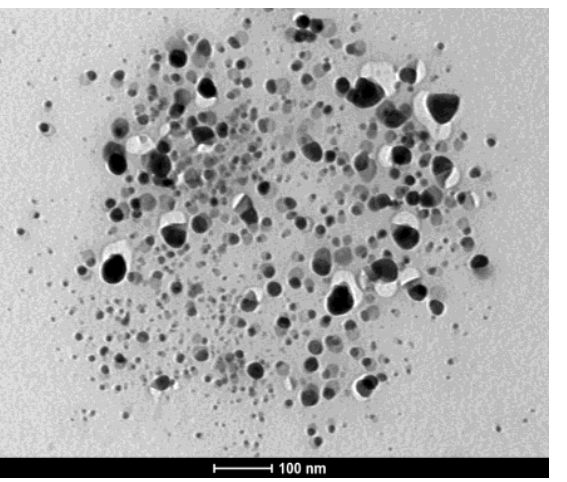

(b)

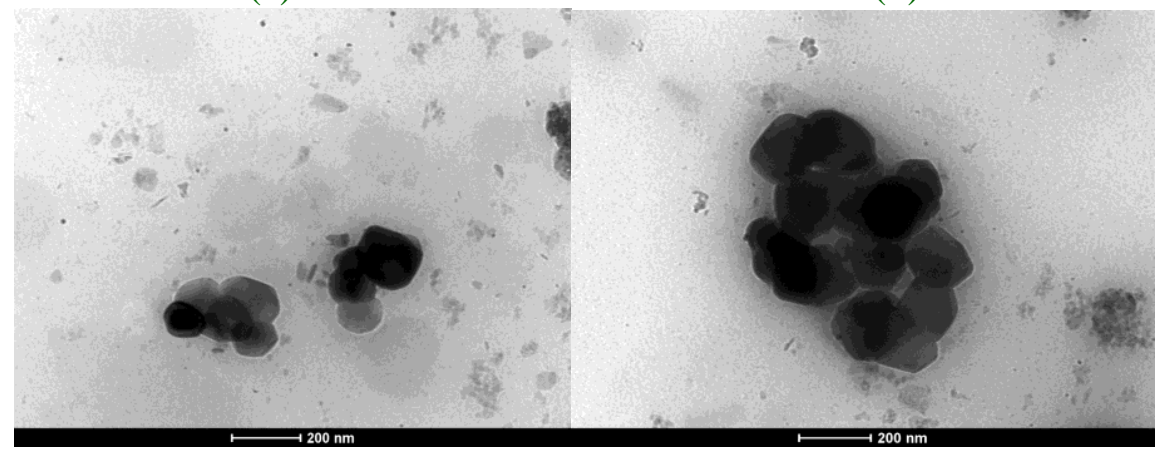

(c)

(d)

\begin{tabular}{|l|l|l|l|l|}
\hline Peak No & S.P. Area Ratio & Mean & S.D & Mode \\
\hline 1 & 1.00 & $16.1 \mathrm{~nm}$ & $0.7 \mathrm{~nm}$ & $16.0 \mathrm{~nm}$ \\
\hline $\mathbf{2}$ & --- & $---\mathrm{nm}$ & $---\mathrm{nm}$ & $---\mathrm{nm}$ \\
\hline $\mathbf{3}$ & --- & $--\mathrm{nm}$ & $---\mathrm{nm}$ & $---\mathrm{nm}$ \\
\hline Total & 1.00 & $16.1 \mathrm{~nm}$ & $0.7 \mathrm{~nm}$ & $16.0 \mathrm{~nm}$ \\
\hline
\end{tabular}

Fig.1 Particle analyzer average size and intensity distribution of $\mathrm{ZnO}$ nanoparticles

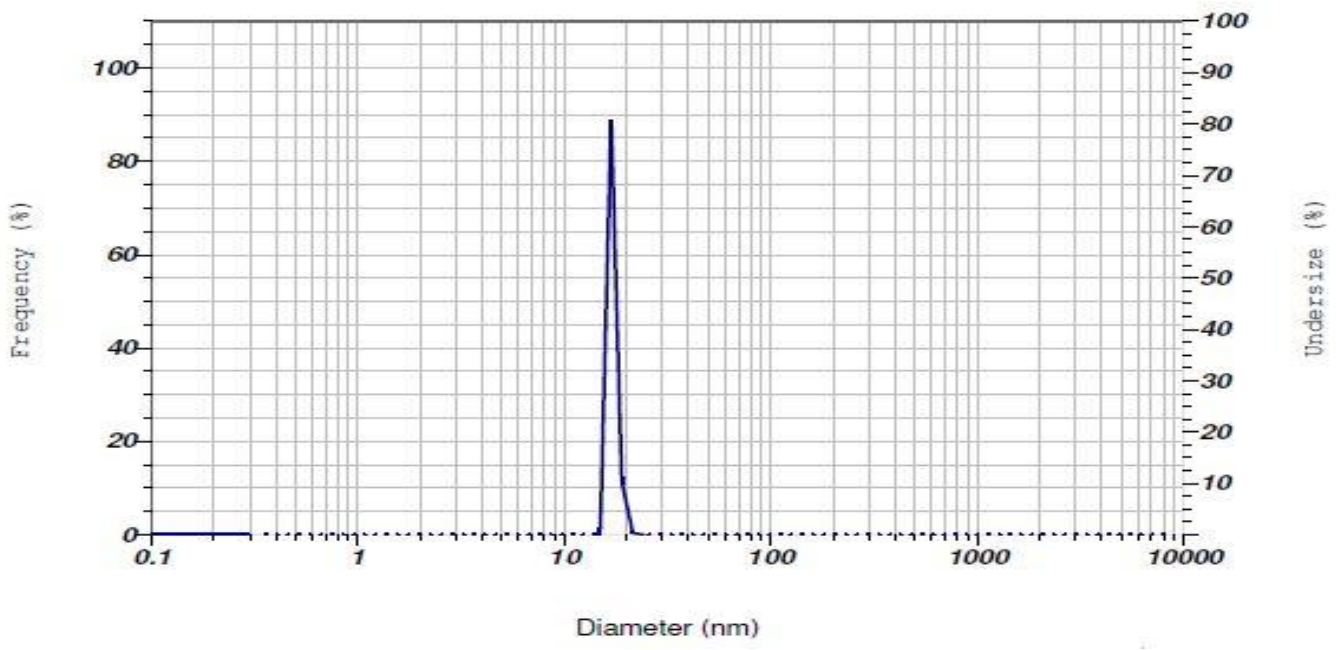


Fig.2 Raman spectra of (a) $\mathrm{Zno,} \mathrm{(b)} \mathrm{Ag}$, (c) $\mathrm{CuO}$ and (d) $\mathrm{TiO}_{2}$ nanoparticles

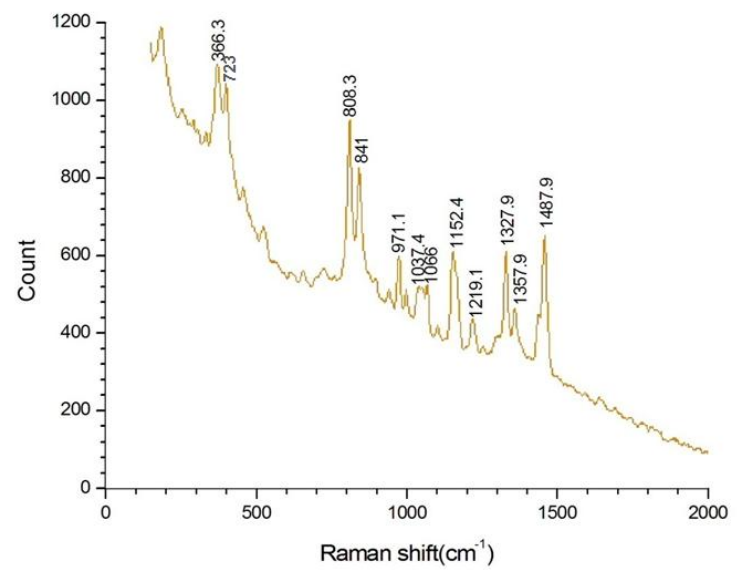

(a)

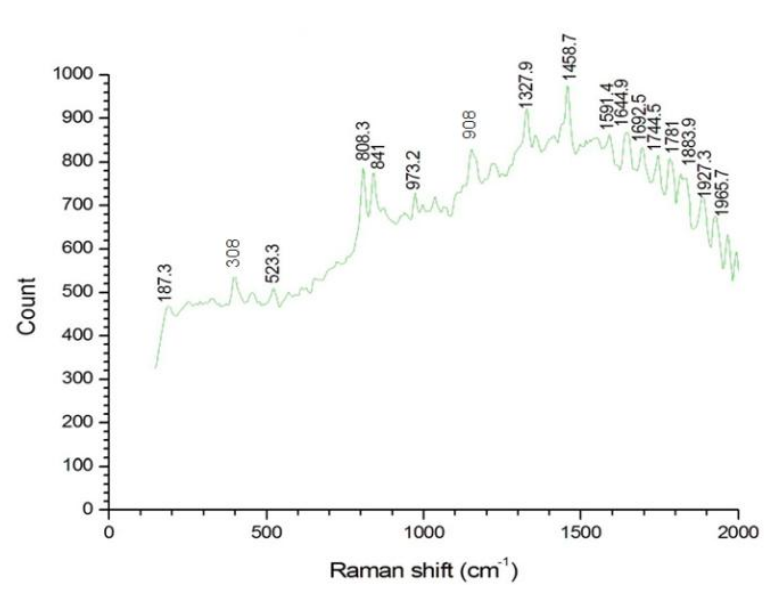

(c)

The powdered, dried NPs kept in a polythene bag were spread to an extent of $1 \mathrm{~cm}^{2}$ and Raman probe was placed on the sample packets without exposing the sample directly to the probe.

\section{Results and Discussion}

\section{Characterization of Nanoparticles ( $\mathrm{ZnO}$,} $\mathrm{Ag}, \mathrm{CuO}$ and $\mathrm{TiO}_{2}$ )

The surface morphology of Zinc Oxide $(\mathrm{ZnO})$, Silver $(\mathrm{Ag})$, Copper Oxide $(\mathrm{CuO})$, and Titanium Oxide $\left(\mathrm{TiO}_{2}\right)$ nanoparticles were examined under SEM, TEM, Particle Size Analyzer and Raman Spectroscopy. The morphology of different nanoparticles

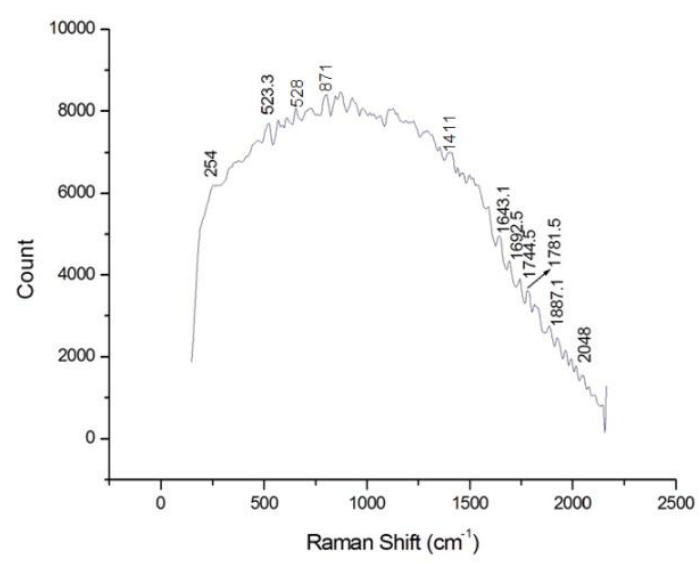

(b)

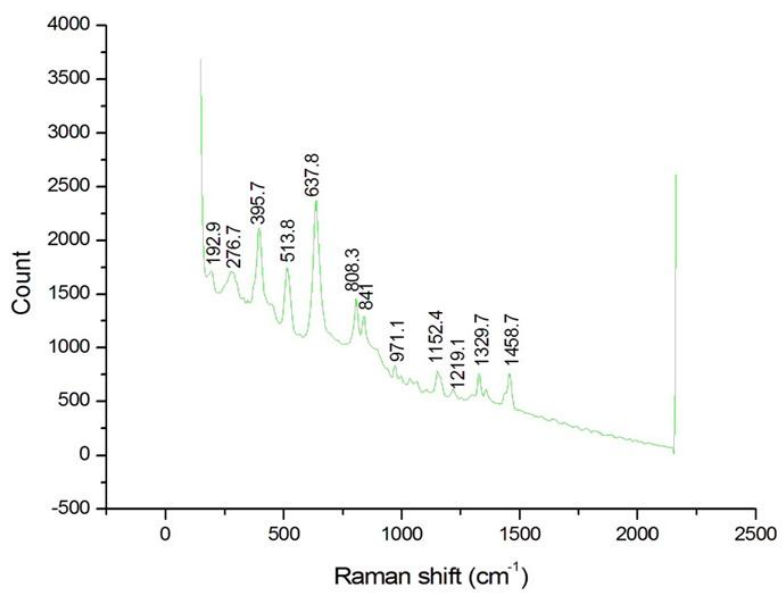

(d)

observed are presented below. The particle size analyzer was used to analyze the size of the particle using laser scattering principle for estimating the average particle size and distribution pattern for synthesized $\mathrm{ZnO}, \mathrm{Ag}$, $\mathrm{CuO}$, and $\mathrm{TiO}_{2}$ nanoparticles. The particle size distribution of $\mathrm{ZnO}, \mathrm{Ag}, \mathrm{CuO}$ and $\mathrm{TiO}_{2}$ was found to be $16,53.7 \mathrm{~nm}, 183 \mathrm{~nm}$ and 387 $\mathrm{nm}$ respectively (Fig. 1).

Raman spectroscopy was employed to identify the chemical composition and to confirm the four different nanoparticles synthesized by observing the peaks. The peaks were observed at $308,908,1152$ and $1280 \mathrm{~cm}^{-1}$ for $\mathrm{CuO}$ while at $528,871,945$ and $1411 \mathrm{~cm}^{-1}$ for $\mathrm{Ag}, 276,637,1327$ and 1458 
$\mathrm{cm}^{-1}$ for $\mathrm{TiO}_{2}$ and 366, 723, 1066 and 1219 $\mathrm{cm}^{-1}$ for $\mathrm{ZnO}$ nanoparticle confirming the respective chemical compounds (Fig. 2).

In this study, the $\mathrm{ZnO}$ nanoparticles were successfully synthesized by direct precipitation method using zinc nitrate as zinc source and $\mathrm{KOH}$ as precipitating agent in aqueous solution. The size range of the generated $\mathrm{ZnO}$ powder was approximately 20-40 nm. In summary we have successfully designed a facile and fast synthesis route to produce $\mathrm{ZnO}$ nanoparticles and finally $\mathrm{ZnO}$ nanoparticles were characterized by UVvisible, TEM and DLS analysis.

\section{References}

Abdul-Baki, A.A., Anderson, J. D., 1973. Vigour deterioration of soybean seeds by multiple criteria. Crop Sci., 13:630 633.

Alocilja, E. C., and S. M. Radke, 2003. Market analysis of biosensors for food safety. Biosensors and Bielectronics, 18: 841-846.

Arami, H., M. Mazloumi., R. Khalifehzadeh., and S. K. Sadmezhaad., 2007. Sonochemical preparation of $\mathrm{TiO}_{2}$ nanoparticles. Materials Letters, 61: 4559-4561.

Basu, R. N., 1994. An appraisal of research on wet and dry physiological seed treatments and their applicability with special reference to tropical and subtropical countries. Seed Sci. \& Technol., 22: 107-126.

Gamiely, S., and Randle, William \& Mills., Harry \& Smittle., D.A. \& Banna., G.I., 1991. Onion Plant Growth, Bulb Quality, and Water Uptake following Ammonium and Nitrate Nutrition. HortScience: a publication of the American Society for Horticultural Science., 26.
ISTA, 2005. International Rules of Seed Testing. Seed Sci. \& Technol., 27: 2732.

Kapri, B., A.K. Sengupta., B.K. De., A.K. Mandal., and R.N. Basu., 2003. Prestorage seed invigouration treatment for improved germinability and field performance of Okra (Hibiscus esculentus). Indian J. of Agric. Sci., 73 (5): 276-9.

Lanje, A.S., Sharma, S.J., Ningthoujam, R.S., Ahn, J.S., Pode, R.B., 2013. Adv Powder Technol. 24, 331-335.

Lee, P.C., Meisel, D., 2005. Adsorption and surface-enhanced Raman of dyes on silver and gold sols. J Phys Chem., 86:3391-5.

Mandal, A. K., B. K. De., R. Saha., and R. N. Basu., 2000. Seed invigouration treatments for improved storability, field emergence and productivity of soybean (Glycine max L.). Seed Sci. \& Technol., 28: 349-355.

Moghaddam, A.B., Nazari, T., Badraghi, J., Kazemzad, M., 2009. Synthesis of ZnO Nanoparticles and Electrodeposition of Polypyrrole/ZnO Nanocomposite Film. Int J Electrochem Sci., 4:247-57.

Nair, R. S. H. Varghese., B. G. Nair., T. Maekawa., Y. Yoshida., and D.S. Kumar., 2010.

Nanoparticulate material delivery to plants. Plant Science, 179: 154-163.

Natarajan, N., Sivasubramanian, K., 2008. Nanotechnology Application in Seed Management Nanotechnology Applications in Agriculture, 43-52.

Senthilkumar, S., 2011. Customizing nanoparticles for the maintenance of seed vigour and viability in Blackgram (Vigna mungo) cv. VBN 4. M.Sc. Thesis, Tamil Nadu Agricultural University, Coimbatore.

Shah, V., Belozerova, I., 2009. Influence of metal nanoparticles on the soil microbial community and germination 
of lettuce seeds. Water, Air and Soil Pollution, 97: 143-48.

Sridhar, C., 2012. Effect of nanoparticles for the maintenance of tomato seed vigour and viability. M.Sc. Thesis, Tamil Nadu Agricultural University, Coimbatore.

Wongpisutpaisan, Charoonsuk, Vittayakorn, and Pecharapa, 2011. Sonochemical synthesis and characterization of Copper Oxide nanoparticles. Energy procedia, 9: 6.

Zhang, F., R. Wang., Q. Xiao., Y. Wang., and

J. Zhang., 2006. Effects of slow/controlled-release fertilizer cemented and coated by nano-materials on biology. II. Effects of slow/controlled-release fertilizer cemented and coated by nano-materials on plants, Nanoscience, 11: 18-26.

Zheng, L., Hong, F., Lu, S., Liu, C., 2005. Effect of nano- $\mathrm{TiO}_{2}$ on strength of naturally aged seeds and growth of spinach. Biol Trace Elem Res., 106: $279-97$.

\section{How to cite this article:}

Anandaraj, K., R. Ilakkiya and Natarajan, N. 2018. Synthesis of Zinc Oxide (ZnO), Silver (Ag), Copper Oxide $(\mathrm{CuO})$ and Titanium Oxide $\left(\mathrm{TiO}_{2}\right)$ Nanoparticles. Int.J.Curr.Microbiol.App.Sci. 7(11): 1514-1521. doi: https://doi.org/10.20546/ijcmas.2018.711.174 